\title{
CARACTERIZAÇÃO DA VEGETAÇÃO DA FAZENDA REMONTA, COUDELARIA DE CAMPINAS, SÃO PAULO ${ }^{1}$
}

\author{
CHARACTERIZATION OF THE VEGETATION OF REMONTA FARM, \\ CAMPINAS HARASS, SÃO PAULO STATE
}

\author{
Daniela Fessel BERTANI ${ }^{2,3}$; Natália Macedo IVANAUSKAS ${ }^{2}$; Flaviana Maluf de SOUZA²; \\ Geraldo Antônio Daher Corrêa FRANCO²; Isabel Fernandes de Aguiar MATTOS4; \\ Marina Mitsue KANASHIRO ${ }^{4}$
}

\begin{abstract}
RESUMO - O objetivo deste estudo foi caracterizar a vegetação da Fazenda Remonta, no município de Campinas-SP. Por meio de fotointerpretação, fez-se um mapa preliminar, que foi usado como base para verificação dos diferentes tipos de cobertura vegetal. Para o levantamento da vegetação, percorreu-se toda a área, registrando-se os atributos estruturais da vegetação, além das espécies arbustivas e arbóreas nativas, exóticas e invasoras. Fez-se também a verificação das classes de vegetação previamente mapeadas para a elaboração do mapa final. A vegetação da Fazenda Remonta é classificada como Floresta Estacional Semidecidual Montana e a cobertura florestal ocupa $41,5 \%$ da propriedade, sendo o restante recoberto, sobretudo, por pastagem. As Áreas de Preservação Permanente somam 59 ha, dos quais $88 \%$ estão cobertos por vegetação nativa. A maior parte dos fragmentos apresenta predomínio de espécies pioneiras e secundárias iniciais, havendo alguns trechos com espécies típicas de estágios mais avançados. Foram observadas 50 espécies nativas de 46 gêneros e 29 famílias. Além destas, foram registradas 12 espécies exóticas, das quais dez são invasoras. Dentre as nativas, duas são consideradas vulneráveis pela lista mundial de espécies ameaçadas de extinção. A Fazenda Remonta apresenta localização estratégica para o estabelecimento de um corredor ecológico entre a Floresta Estadual da Serra D’Água e a Estação Ecológica de Valinhos, permitindo o fluxo gênico entre as populações de plantas e animais. Essas características ressaltam a importância da manutenção da vegetação para a conservação da biodiversidade regional, sobretudo em áreas altamente urbanizadas e com fortes e constantes pressões antrópicas.
\end{abstract}

Palavras-chave: Floresta Estacional Semidecidual; Mata Atlântica; composição florística.

\begin{abstract}
The aim of this study was to characterize the vegetation of the Remonta Farm, located in Campinas, southeastern Brazil. Photointerpretation was used to provide a preliminary map of the farm, which was used as a basis for the assessment of the different vegetation cover types. For the vegetation field survey, the whole farm was assessed, and structural attributes of the community, as well as native, exotic and invasive species were recorded. The cover types described in the preliminary map were verified in the field for the preparation of the final map. The vegetation of the farm is composed of Seasonal Semideciduous Montane Forest, which accounts for $41.5 \%$ of the farm area; the remaining area is covered mostly by pastures. The Permanent Preservation Areas add up to 59 ha, and $88 \%$ of them are covered by native vegetation. Most forest remnants are dominated by pioneer and early secondary species, but there are some patches in which late secondary species were also present. Fifty native species were recorded, belonging to 46 genera and 29 families. Twelve exotic species, including 10 invasive ones, were also recorded. Two of the native species identified are described as vulnerable in the global plant red list. The farm is strategically located for the establishment of an ecological corridor between the State Forest Serra D'Água and Valinhos Ecological Station, allowing gene flow between populations of plants and animals. These characteristics highlight
\end{abstract}

\footnotetext{
${ }^{1}$ Recebido para análise em 10.9.2013. Aceito para publicação em 19.9.2014.

${ }^{2}$ Instituto Florestal, Seção de Ecologia Florestal, Rua do Horto, 931, 02377-000 São Paulo, SP, Brasil.

3 Autor para correspondência: Daniela Fessel Bertani - dfbertani@uol.com.br

${ }^{4}$ Instituto Florestal, Seção de Introdução, Rua do Horto, 931, 02377-000, São Paulo, SP, Brasil.
} 
the importance of maintaining the vegetation for the conservation of regional biodiversity, especially in highly urbanized areas with strong and constant anthropogenic pressure.

Keywords: Seasonal Semideciduous Forest; Atlantic Forest; floristic composition

\section{INTRODUÇÃO}

O Estado de São Paulo possui 3,3 milhões de hectares de cobertura vegetal natural, o que representa $13,4 \%$ da sua área total (Kronka et al., 2005). Da área que resta, a maior parte se encontra no complexo Serra do Mar e de Paranapiacaba, em regiões de difícil acesso, onde a ocupação humana não foi possível. Nessas regiões, a vegetação remanescente predominante é a Floresta Ombrófila Densa, que é o tipo florestal atlântico mais bem representado em unidades de conservação paulistas (Durigan et al., 2009).

Por sua vez, a Floresta Estacional Semidecidual, comumente denominada de "Mata Atlântica de Interior" ou "Floresta do Paraná", ocupava os solos mais férteis de todo o domínio da Mata Atlântica, com topografia favorável à agricultura, de modo que foi o primeiro e o mais severamente devastado dentre os tipos de vegetação previamente existentes no interior paulista (Ivanauskas e Assis, 2012).

Devido à redução da vegetação nativa no Estado de São Paulo, os remanescentes de Floresta Estacional ainda existentes no interior do Estado assumem elevada importância para a conservação da biodiversidade, independentemente de seu tamanho e do seu estado de degradação (Santin, 1999; Kotchetkoff-Henriques, 2003; Rodrigues; Bononi, 2008).

Esses fragmentos naturais podem exercer papel ainda mais relevante para a conservação da biodiversidade, se forem devidamente protegidos e adequadamente manejados. Não menos importante é a conexão desses fragmentos na paisagem, otimizando a conservação do pouco que sobrou de vegetação nativa no Estado de São Paulo (Durigan et al., 2008). A área da Fazenda Remonta tem uma grande importância na paisagem por sua função de corredor ecológico, pois estabelece uma ligação entre duas unidades de conservação: a Floresta Estadual Serra D’Água (município de Campinas) e a Estação Ecológica de Valinhos (município de Valinhos). Assim, o objetivo deste estudo foi caracterizar a cobertura vegetal da Fazenda Remonta, dando fundamentos para a preservação da área num contexto de paisagem, de modo a promover o aumento e/ou a preservação da biodiversidade regional.

\section{MATERIAIS E MÉTODOS}

A Fazenda Remonta (Coudelaria) localiza-se entre os municípios de Campinas e Valinhos, Estado de

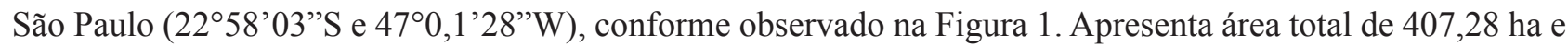
altitude de 700 m. O clima da região de Campinas, segundo a classificação de Köppen (1948), é do tipo Cwa subtropical de inverno seco, com temperaturas inferiores a $18^{\circ} \mathrm{C}$, e verão quente, com temperaturas superiores a $22^{\circ} \mathrm{C}$. Além da grande malha urbana dentro da qual está inserida, a fazenda faz divisa com a Estação Ecológica de Valinhos, com área de 17 ha, e com a Floresta Estadual da Serra D’Água, que possui 51,20 ha (Figura 2).

No mapeamento da vegetação, adaptaram-se os procedimentos descritos por Lueder (1959) e Spurr (1960), que identificam e classificam a vegetação utilizando os elementos da imagem fotográfica, como cor, tonalidade, textura, entre outros. A observação de atributos como porte e densidade da vegetação complementou essa análise e orientou o mapeamento detalhado. Foram considerados de porte arbóreo médio a alto, os adensamentos de árvores com altura acima de $15 \mathrm{~m}$ de altura, e de porte arbóreo médio a baixo, com altura variando entre 8 e $15 \mathrm{~m}$.

Para este procedimento, utilizou-se a Ortofotocarta Digital na escala 1:5.000, do ano de 2007, da Empresa Paulista de Planejamento Metropolitano S/A - EMPLASA. As informações obtidas foram então 


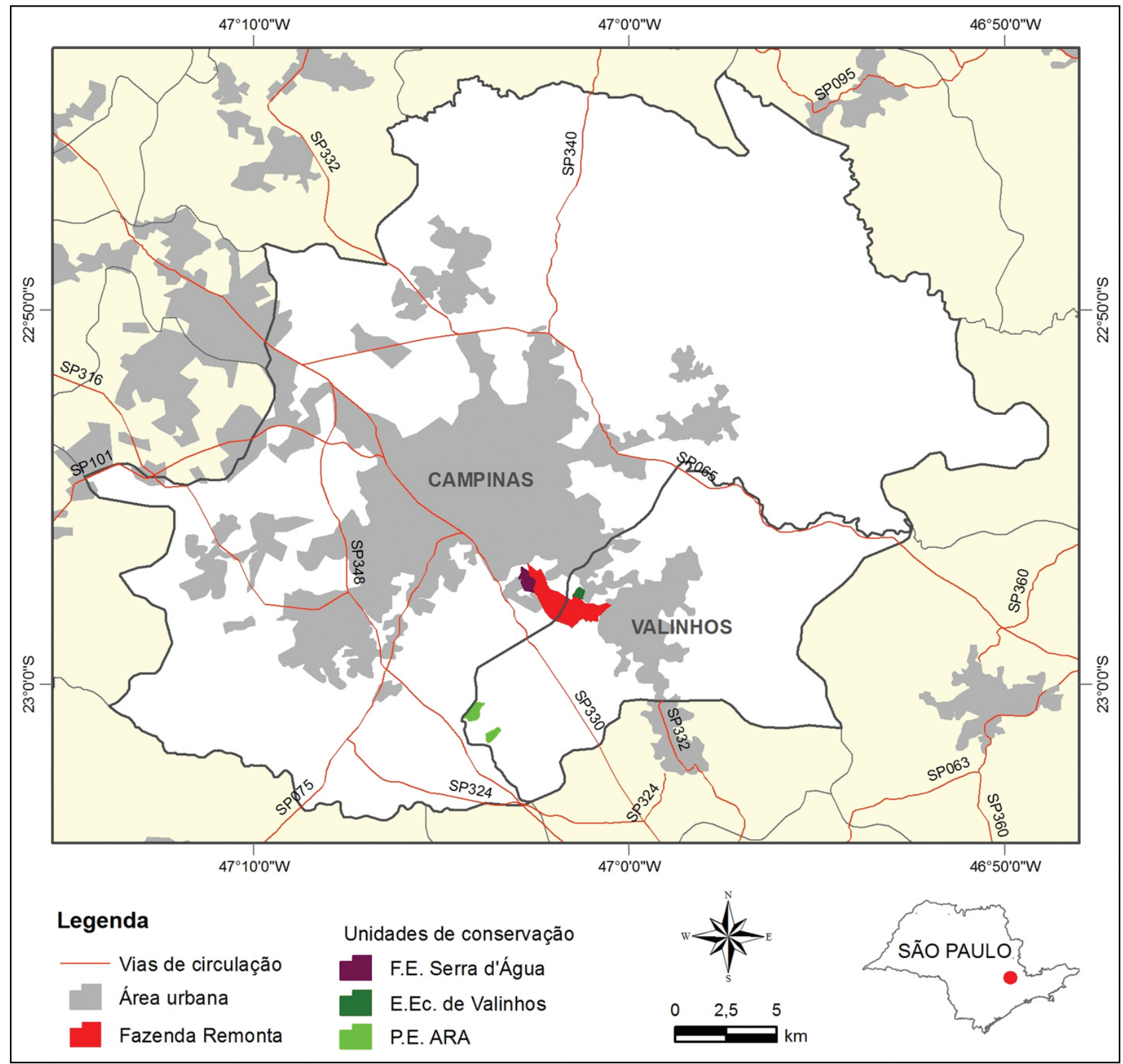

Figura 1. Localização da Fazenda Remonta no Estado de São Paulo, município de Campinas e unidades de conservação do entorno.

Figure 1. Remonta Farm Location in the state of Sao Paulo, municipality of Campinas and surrounding protected areas.

espacializadas sobre as Folhas Valinhos (SF-23-Y-A-V-4-SE-F) e Campinas (SF-23-Y-A-V-4-SE-D), na escala 1:10.000 de 1979, 1. ${ }^{a}$ ed., do Plano Cartográfico do Estado de São Paulo, da Secretaria de Economia e Planejamento, utilizando-se, na transferência dos dados, o Sistema de Informações Geográficas - SIG ArcMap 9.3, elaborando-se, desta forma, um mapa preliminar. Durante os trabalhos de campo, fez-se a verificação dos padrões estabelecidos, apontando-se eventuais divergências para a realização de ajustes e a elaboração do mapa final. O sistema de classificação da vegetação adotado foi o proposto pelo Instituto Brasileiro de Geografia e Estatística (2012). Também foram mapeadas as Áreas de Preservação Permanente (APPs) geradas pelos cursos d'água e lagos existentes na propriedade, aplicando-se um raio de $50 \mathrm{~m}$ para as nascentes e uma faixa de $30 \mathrm{~m}$ de largura ao longo de cada margem de rios e no entorno de lagoas (Brasil, 2012).

A lista das espécies de plantas vasculares na Fazenda Remonta foi obtida por meio do levantamento de campo, realizado em maio de 2012, percorrendo-se os limites e caminhos no interior da unidade, de forma a 


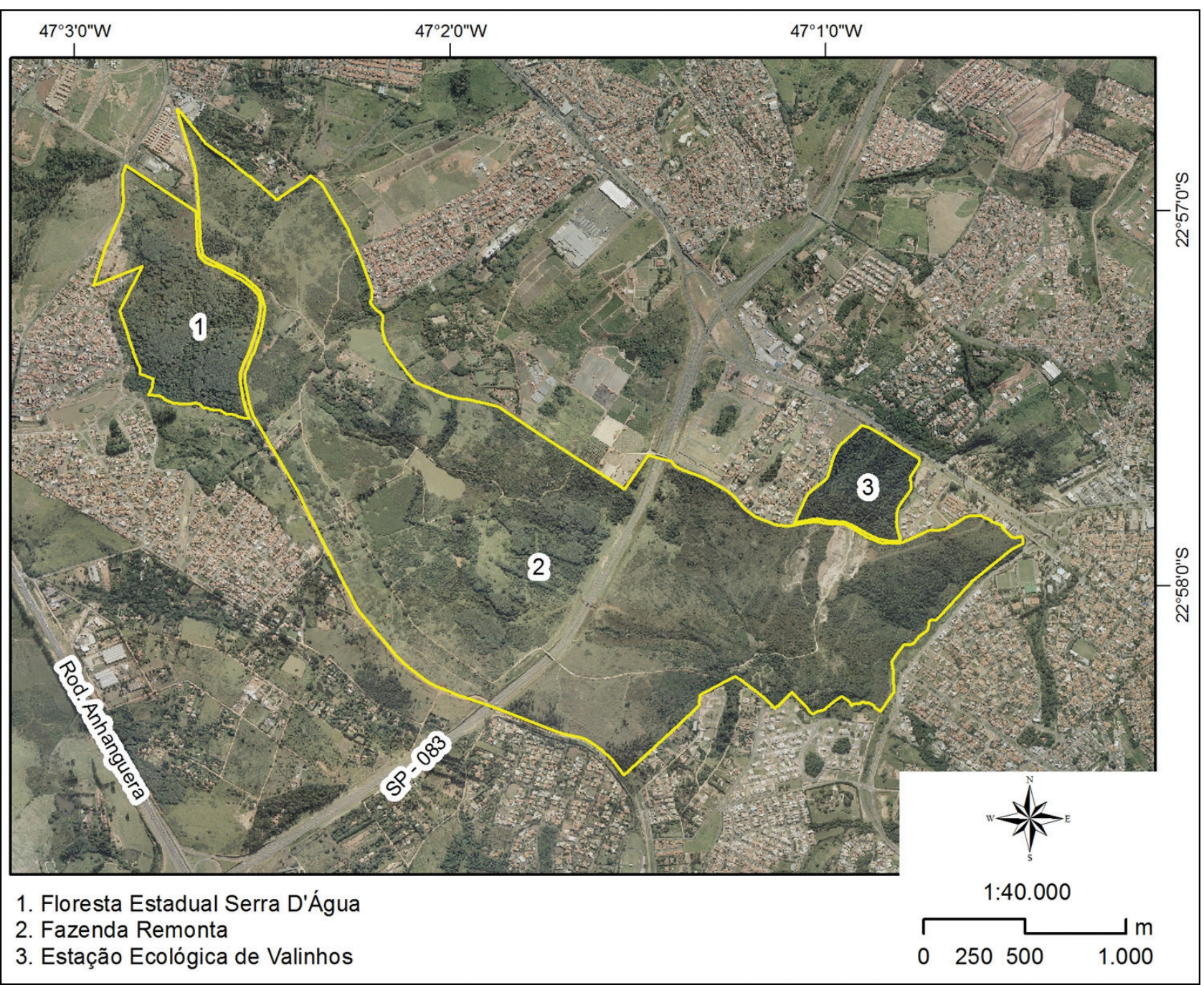

Figura 2. Localização da Fazenda Remonta (2) no município de Campinas e das unidades de conservação que fazem divisa: Floresta Estadual da Serra D’Água (1) e Estação Ecológica de Valinhos (3).

Figure 2. Location of Remonta Farm (2) in the municipality of Campinas and the surroundings conservation units: Serra D’Água Forest Station (1) and Valinhos Ecological Station (3).

abranger a maior variedade possível de tipos vegetacionais. Durante o caminhamento, foram listadas as espécies mais comuns nas fitofisionomias previamente mapeadas. É importante ressaltar que o inventário florístico em campo foi expedito, em função da dificuldade de acesso e de situações insalubres, frente ao elevado grau de carrapatos potenciais transmissores de febre maculosa no local. O material botânico coletado foi identificado através de comparação com exsicatas em herbários e uso de bibliografia específica. A grafia dos nomes científicos e a checagem de sinônimos foram feitas com base na lista de espécies da Flora do Brasil (2014), com classificação das famílias baseada em The Angiosperm Phylogeny Group III (2009) e Souza e Lorenzi (2012).

Com base na listagem obtida em campo, foram destacadas as espécies ameaçadas e exóticas registradas no interior da unidade. As listas oficiais das espécies vegetais ameaçadas de extinção utilizadas para consulta foram: a) Lista oficial de espécies ameaçadas de extinção no Estado de São Paulo (Mamede et al., 2007); b) Lista oficial das espécies da flora brasileira ameaçada de extinção (Brasil, 2008); c) Lista vermelha de espécies ameaçadas de extinção globalmente (Union For Conservation Of Nature, 2014). As espécies nativas foram classificadas em grupos sucessionais com base nos critérios de Gandolfi et al., (1995).

Foram consideradas espécies exóticas aquelas ausentes na lista oficial de espécies nativas no Estado de São Paulo (Wanderley et al., 2011) e/ou com ocorrência natural não registrada para os tipos vegetacionais 


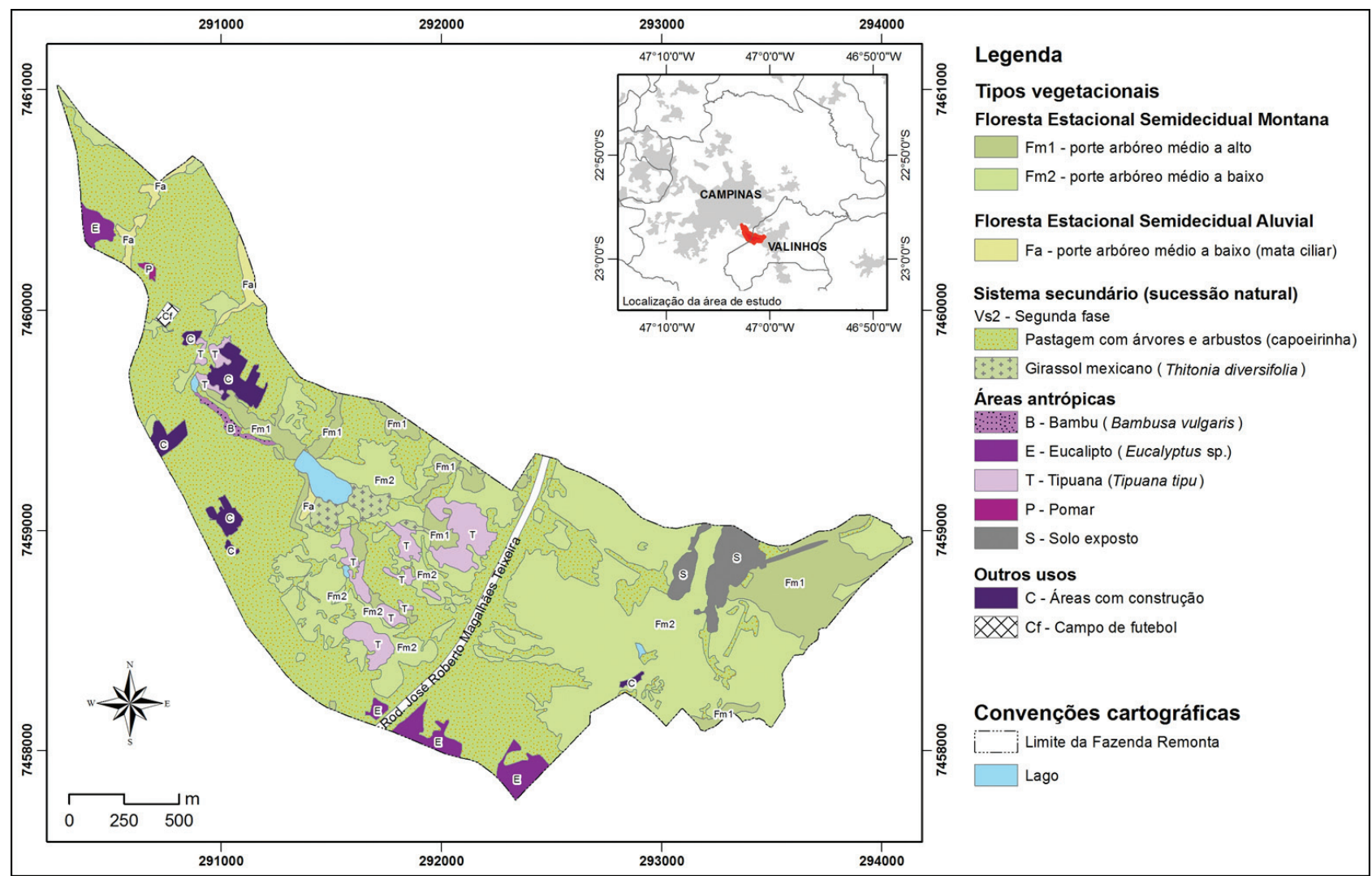

Figura 3. Tipos vegetacionais e usos da terra da Fazenda Remonta, Campinas-SP.

Figure 3. Vegetation types and land use in Remonta Farm, municipality of Campinas, Sao Paulo state.

do município de Campinas. Foram consideradas espécies exóticas invasoras aquelas presentes no relatório do Grupo de Trabalho sobre espécies exóticas invasoras no Estado de São Paulo (Azevedo, 2009).

\section{RESULTADOS E DISCUSSÃO}

\subsection{Fitofisionomias da Fazenda Remonta}

A Fazenda Remonta está presente em área de ocorrência da Floresta Estacional Semidecidual. O termo "estacional" expressa as transformações de aspecto de uma comunidade, conforme as estações do ano (Academia De Ciências Do Estado De São Paulo, 1997). É atribuído a regiões do globo terrestre que apresentam alta sazonalidade: num mesmo ano, existe um período seco e outro chuvoso. De acordo com o Instituto Brasileiro de Geografia e Estatística (2012), a Floresta Estacional está sujeita a um período desfavorável ao crescimento, que se traduz num longo período de estiagem acentuada para o clima tropical (médias de $22^{\circ} \mathrm{C}, 4$ a 6 meses secos) ou num frio intenso (seca fisiológica) para o clima subtropical (médias de $18^{\circ} \mathrm{C}$, mas com pelo menos três meses com temperaturas de inverno inferiores a $15^{\circ} \mathrm{C}$ ).

A Floresta Estacional Semidecidual responde a este período desfavorável com um ritmo sazonal: no período desfavorável do ano, de 20 a 50\% das árvores do estrato superior perdem suas folhas, com diminuição significativa na cobertura do dossel. Essa maior variação e disponibilidade de luz para as espécies da submata afetam a dinâmica florestal, criando "clareiras de deciduidade" (Gandolfi et al., 2009). Embora os padrões fenológicos de floração e queda de folhas sejam marcadamente sazonais, a frutificação é pouco sazonal, mesmo 
considerando a ocorrência de maior número de espécies com frutos maduros na estação seca ou na transição da seca para a úmida (Morellato, 2003).

A Floresta Estacional Semidecidual presente na Fazenda Remonta foi mapeada de acordo com as faixas altimétricas propostas por Instituto Brasileiro de Geografia e Estatística (2012). Assim, nas áreas de interflúvio ocorre a Floresta Estacional Semidecidual Montana e, ao longo dos cursos d'água, a Floresta Estacional Semidecidual Aluvial (Figura 3). Estas duas fitofisionomias ocupam $41 \%$ da área da Fazenda Remonta (Tabela 1), mas a maior parte dos remanescentes apresenta sinais de degradação no passado, provavelmente em decorrência de cortes seletivos e/ou ocorrência de incêndios.

\subsubsection{Floresta Estacional Semidecidual Montana}

Na Fazenda Remonta, a Floresta Estacional Montana foi subdividida em duas categorias (Figura 3), segundo os códigos Fm1 e Fm2, de acordo com o seu desenvolvimento e o estádio de conservação.

Trechos de floresta descritos como de porte médio a alto (Fm1) apresentam árvores emergentes de $20 \mathrm{~m}$ de altura, mas distanciadas entre si, resultando em dossel irregular. Estes locais, embora ocupem pequena porção na área leste da fazenda, cerca de $8 \%$ da propriedade (Tabela 1), abrigam populações de espécies finais de sucessão (Tabela 2), sendo, portanto, as florestas em melhor estado de conservação mapeadas na unidade. São exemplos de tais espécies: Cedrela fissilis (cedro-rosa), Cordia trichotoma (louro-pardo), Erythrina falcata (mulungu) e Myroxylon peruiferum (cabreúva). A presença destas espécies está associada à proximidade com a Estação Ecológica de Valinhos, compondo importante corredor ecológico.

Tabela 1. Tipos vegetacionais e uso do solo na Fazenda Remonta, Campinas, SP.

Table 1. Vegetation types and land use in Remonta Farm, municipality of Campinas, Sao Paulo state.

Tipos de vegetação e uso do solo

Área

ha $\%$

\section{Floresta Estacional Semidecidual Montana}

Fm1 - porte arbóreo médio a alto

Fm2 - porte arbóreo médio a baixo

130,54

\section{Floresta Estacional Semidecidual Aluvial}

$\mathrm{Fa}$ - porte arbóreo médio a baixo (mata ciliar)

$\begin{array}{rr}4,46 & 1,1 \\ 3,87 & 0,9 \\ 183,51 & 45,1\end{array}$

Girassol mexicano [Tithonia diversifolia (Hemsl.) A.Gray]

183,51

\section{Áreas antrópicas}

B - Bambu (Bambusa vulgaris Schrad. ex J.C.Wendl.)

$$
1,14
$$

E - Eucalipto (Eucalyptus sp.)

T - Tipuana [Tipuana tipu (Hemsl.) A.Gray]

P - Pomar

S - Solo exposto

9,08

\section{Outros usos}

C - Área com construção

Cf - Campo de futebol 
BERTANI, D.F. et al. Caracterização da vegetação da Fazenda Remonta, Coudelaria de Campinas, São Paulo

Tabela 2. Espécies vegetais registradas durante levantamento expedito da vegetação da Fazenda Remonta, Campinas-SP. Table 2. Plant species recorded during a quick survey of the vegetation of Remonta Farm, municipality of Campinas, Sao Paulo state.

\begin{tabular}{|c|c|c|c|c|}
\hline Família & Espécie & Nome popular & Origem & GS \\
\hline Anacardiaceae & Lithrea molleoides (Vell.) Engl. & aroeira-brava & $\mathrm{N}$ & $\mathrm{Si}$ \\
\hline Arecaceae & Syagrus comosa (Mart.) Mart. & macaúba & $\mathrm{N}$ & $\mathrm{P}$ \\
\hline Asteraceae & Gochnatia polymorpha (Less.) Cabrera & cambará & $\mathrm{N}$ & $\mathrm{P}$ \\
\hline Asteraceae & Tithonia diversifolia (Hemsl.) A.Gray & girassol-mexicano & $\mathrm{Ei}$ & $\mathrm{Na}$ \\
\hline Bignoniaceae & Handroanthus ochraceus (Cham.) Mattos & ipê-amarelo & $\mathrm{N}$ & $\mathrm{Si}$ \\
\hline Bignoniaceae & Tecoma stans (L.) Juss. ex Kunth & ipê-de-jardim & $\mathrm{Ei}$ & $\mathrm{Na}$ \\
\hline Boraginaceae & Cordia ecalyculata Vell. & café-de-bugre & $\mathrm{N}$ & $\mathrm{Si}$ \\
\hline Boraginaceae & Cordia trichotoma (Vell.) Arráb. ex Steud. & louro-pardo & $\mathrm{N}$ & $\mathrm{Si}$ \\
\hline Burseraceae & Protium heptaphyllum (Aubl.) Marchand & almecega & $\mathrm{N}$ & St \\
\hline Cannabaceae & Trema micranta (L.) Blume & candiúba, crindiúva & $\mathrm{N}$ & $\mathrm{P}$ \\
\hline Erythroxylaceae & Erythroxylum deciduum A.St.-Hil. & galinha-choca & $\mathrm{N}$ & $\mathrm{Si}$ \\
\hline Euphorbiaceae & Croton floribundus Spreng. & capixingui & $\mathrm{N}$ & $\mathrm{P}$ \\
\hline Euphorbiaceae & Sapium glandulosum (L.) Morong & leiteiro & $\mathrm{N}$ & $\mathrm{P}$ \\
\hline Fabaceae & Bauhinia forficata Link & pata-de-vaca & $\mathrm{N}$ & $\mathrm{Si}$ \\
\hline Fabaceae & Copaifera langsdorffii Desf. & copaíba & $\mathrm{N}$ & St \\
\hline Fabaceae & Erythrina falcata Benth. & mulungu & $\mathrm{N}$ & St \\
\hline Fabaceae & Inga sessilis (Vell.) Mart. & ingá-ferradura & $\mathrm{N}$ & $\mathrm{Si}$ \\
\hline Fabaceae & Lonchocarpus campestris Mart. ex Benth. & feijão-cru & $\mathrm{N}$ & $\mathrm{Si}$ \\
\hline Fabaceae & Machaerium nyctitans (Vell.) Benth. & bico-de-pato-de-espinho & $\mathrm{N}$ & $\mathrm{Si}$ \\
\hline Fabaceae & Machaerium villosum Vogel * & jacarandá-paulista & $\mathrm{N}$ & St \\
\hline Fabaceae & Myroxylon peruiferum L.f.* & cabreúva & $\mathrm{N}$ & $\mathrm{St}$ \\
\hline Fabaceae & Piptadenia gonoacantha (Mart.) J.F.Macbr. & pau-jacaré & $\mathrm{N}$ & $\mathrm{Si}$ \\
\hline Fabaceae & Platypodium elegans Vogel & jacarandá-do-campo & $\mathrm{N}$ & $\mathrm{Si}$ \\
\hline Fabaceae & Schizolobium parahyba (Vell.) Blake & guapuruvu & $\mathrm{Ei}$ & $\mathrm{Na}$ \\
\hline Fabaceae & Senegalia polyphylla (DC.) Britton \& Rose & monjoleiro & $\mathrm{N}$ & $\mathrm{Si}$ \\
\hline Fabaceae & $\begin{array}{l}\text { Senna macranthera (DC. ex Collad.) H.S.Irwin \& } \\
\text { Barneby }\end{array}$ & manduirana & $\mathrm{N}$ & $\mathrm{P}$ \\
\hline Fabaceae & Senna splendida (Vogel) H.S.Irwin \& Barneby & manduirana & $\mathrm{N}$ & $\mathrm{P}$ \\
\hline Fabaceae & Tipuana tipu (Benth.) Kuntze & tipuana & $\mathrm{Ei}$ & $\mathrm{Na}$ \\
\hline Lamiaceae & Aegiphila integrifolia (Jacq.) Moldenke & tamanqueira & $\mathrm{N}$ & $\mathrm{P}$ \\
\hline Lauraceae & Nectandra megapotamica (Spreng.) Mez & canelinha & $\mathrm{N}$ & St \\
\hline Lecythidaceae & Cariniana estrellensis (Raddi) Kuntze & jequitibá-branco & $\mathrm{N}$ & St \\
\hline Malvaceae & Ceiba speciosa (A.St.-Hil) Ravenna & paineira & $\mathrm{N}$ & $\mathrm{Si}$ \\
\hline Malvaceae & Guazuma ulmifolia Lam. & mutambo & $\mathrm{N}$ & $\mathrm{Si}$ \\
\hline Malvaceae & Luehea divaricata Mart. \& Zucc. & açoita-cavalo & $\mathrm{N}$ & $\mathrm{Si}$ \\
\hline Meliaceae & Cabralea canjerana (Vell.) Mart. & canjerana & $\mathrm{N}$ & St \\
\hline Meliaceae & Cedrela fissilis Vell. & cedro-rosa & $\mathrm{N}$ & St \\
\hline Meliaceae & Melia azedarach L. & cinamomo & $\mathrm{Ei}$ & $\mathrm{Na}$ \\
\hline Meliaceae & Trichilia pallida Sw. & catiguá & $\mathrm{N}$ & St \\
\hline Moraceae & Maclura tinctoria (L.) D.Don ex Steud. & taiuva & $\mathrm{N}$ & $\mathrm{Si}$ \\
\hline
\end{tabular}

*Espécievulnerávelàextinçãoemescalaglobal(UnionForConservationOfNature,2014).Origem:N-NativaemFlorestaEstacionalSemidecidual;Ex-Exótica;Ei-Exóticainvasora.GS-Gruposucessional:P-Pioneira,Si-Secundáriainicial,St-Secundáriatardia,Na-Nãoseaplica. *Species vulnerable to extinction globally (Union For Conservation Of Nature, 2014). Origin: N - Native in semideciduous forest; Ex Exotic; Ei - Exotic invasive. GS - Successional Group: P - Pioneer Si - Early successional, St - Late-successional Na - Not applicable. 
Tabela 2. Continuação...

Table 2. Continued...

\begin{tabular}{|c|c|c|c|c|}
\hline Família & Espécie & Nome popular & Origem & GS \\
\hline Musaceae & Musa paradisíaca $\mathrm{L}$. & bananeira & Ex & $\mathrm{Na}$ \\
\hline Myrtaceae & Campomanesia guazumifolia (Cambess.) O.Berg & sete-capotes & $\mathrm{N}$ & St \\
\hline Myrtaceae & Eucalyptus sp. & eucalipto & Ex & $\mathrm{Na}$ \\
\hline Myrtaceae & Myrcia splendens (Sw.) DC. & guamirim & $\mathrm{N}$ & $\mathrm{P}$ \\
\hline Myrtaceae & Psidium guajava L. & goiabeira & $\mathrm{Ei}$ & $\mathrm{Na}$ \\
\hline Peraceae & Pera glabrata (Schott) Poepp. ex Baill. & tabocuva & $\mathrm{N}$ & $\mathrm{Si}$ \\
\hline Phytolaccaceae & Seguieria langsdorffii Moq. & limão-bravo & $\mathrm{N}$ & $\mathrm{Si}$ \\
\hline Pinaceae & Pinus sp. & pinheiro & $\mathrm{Ei}$ & $\mathrm{Na}$ \\
\hline Poaceae & Bambusa vulgaris Schrad. ex J.C.Wendl. & bambu-verde-amarelo & $\mathrm{Ei}$ & $\mathrm{Na}$ \\
\hline Poaceae & Chusquea sp. & taquarinha & $\mathrm{N}$ & $\mathrm{P}$ \\
\hline Poaceae & Phyllostachys aurea Rivière \& C. Rivière & bambu-vara-de-pescar & $\mathrm{Ei}$ & $\mathrm{Na}$ \\
\hline Primulaceae & Myrsine umbellata Mart. & capororoca & $\mathrm{N}$ & $\mathrm{P}$ \\
\hline Proteaceae & $\begin{array}{l}\text { Roupala montana var. brasiliensis (Klotzsch) } \\
\text { K.S.Edwards }\end{array}$ & carne-de-vaca & $\mathrm{N}$ & St \\
\hline Rutaceae & Citrus X aurantium L. & limão-rosa & $\mathrm{Ei}$ & $\mathrm{Na}$ \\
\hline Rutaceae & Zanthoxylum rhoifolium Lam. & mamica-de-porca & $\mathrm{N}$ & $\mathrm{Si}$ \\
\hline Salicaceae & Casearia sylvestris $\mathrm{Sw}$. & guaçatonga & $\mathrm{N}$ & $\mathrm{Si}$ \\
\hline Sapindaceae & Cupania emarginata Cambess. & camboatá & $\mathrm{N}$ & $\mathrm{Si}$ \\
\hline Siparunaceae & Siparuna guianensis Aubl. & negamina & $\mathrm{N}$ & St \\
\hline Solanaceae & Solanum granulosoleprosum Dunal & jurubeba & $\mathrm{N}$ & $\mathrm{P}$ \\
\hline Solanaceae & Solanum lycocarpum A.St.-Hil. & lobeira & $\mathrm{N}$ & $\mathrm{P}$ \\
\hline Urticaceae & Cecropia pachystachya Trécul & embaúba-branca & $\mathrm{N}$ & $\mathrm{P}$ \\
\hline Verbenaceae & Aloysia virgata (Ruiz \& Pav.) Juss. & cambará-de-lixa & $\mathrm{N}$ & $\mathrm{P}$ \\
\hline Verbenaceae & Citharexylum myrianthum Cham. & pau-viola & $\mathrm{N}$ & $\mathrm{P}$ \\
\hline
\end{tabular}

*Espécievulnerávelàextinçãoemescalaglobal(UnionForConservationOfNature,2014).Origem:N-NativaemFlorestaEstacionalSemidecidual;Ex-Exótica;Ei-Exóticainvasora.GS-Gruposucessional:P-Pioneira,Si-Secundáriainicial,St-Secundáriatardia,Na-Nãoseaplica. *Species vulnerable to extinction globally (Union For Conservation Of Nature, 2014). Origin: $\mathrm{N}$ - Native in semideciduous forest; Ex Exotic; Ei - Exotic invasive. GS - Successional Group: P - Pioneer Si - Early successional, St - Late-successional Na - Not applicable.

A maior parte das florestas presentes nas áreas de interflúvio, 32\% da área da Fazenda Remonta (Tabela 1), apresenta porte médio a baixo, com árvores entre 8 e $15 \mathrm{~m}$ de altura, com elevada densidade de clareiras e trepadeiras nas situações de borda (Figura 3), código Fm2. São florestas que necessitam de proteção contra a ocorrência de fogo e de manejo para o controle das nativas superabundantes e de espécies exóticas invasoras.

\subsubsection{Floresta Estacional Semidecidual Aluvial}

Segundo o sistema de classificação da vegetação brasileira (Instituto Brasileiro De Geografia E Estatística, 2012), as florestas aluviais são encontradas sempre nas planícies e em alguns terraços mais antigos das calhas dos rios. Na Fazenda Remonta, estas florestas ocorrem na margem ou muito próximas do curso d'água (Figura 4). Apresentam maior perenidade foliar, comparadas àquela de interflúvio, em função da maior disponibilidade de água proveniente do lençol freático elevado e do pulso de inundação. Embora ocupem áreas 


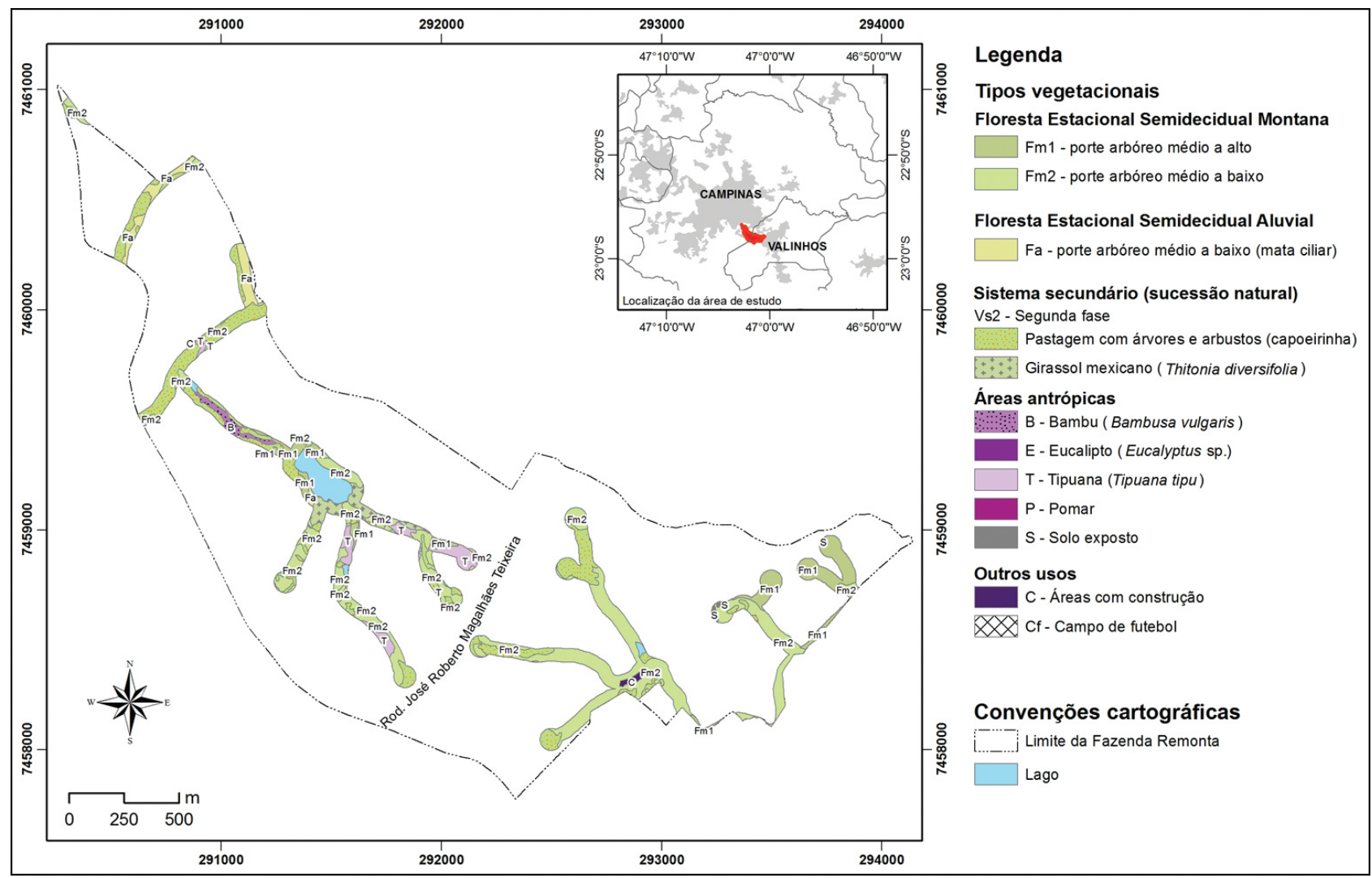

Figura 4. Uso e ocupação das Áreas de Preservação Permanente (APPs) da Fazenda Remonta, Campinas-SP.

Figure 4. Use and occupation of Permanent Preservation Areas (PPA), Remonta Farm, municipality of Campinas, Sao Paulo state.

de preservação permanente, estas florestas ciliares ocupam pequena porção da propriedade (somente 1\% da área da fazenda) e encontram-se bastante degradadas, com presença de espécies exóticas invasoras (Tabelas 1 e 2).

Este tipo florestal está sempre associado às planícies fluviais presentes em áreas de preservação permanente (APPs) da Fazenda Remonta (Figura 4). No entanto, é importante destacar que o relevo da propriedade é colinoso (vide relatório do meio físico), o que resulta em APP composta tanto por florestas estacionais aluviais (nas áreas inundáveis) quanto por florestas estacionais montanas (parte dos morros e colinas em situações de cursos d'água mais encaixados).

\subsubsection{Sistema secundário}

Na classificação adotada pelo Instituto Brasileiro de Geografia e Estatística (2012), são incluídas, no sistema secundário, as áreas onde houve intervenção humana para o uso da terra, seja com a finalidade mineradora, agrícola ou pecuária, configurando, portanto, trechos florestais que foram sujeitos a corte raso.

$\mathrm{Na}$ Fazenda Remonta, foram incluídos no sistema secundário trechos de vegetação natural, em que o grau de intervenção humana foi tão severo que acabou por deteriorar a estrutura florestal - Código Vs2 (Figura 3). Atualmente, estas áreas encontram-se abandonadas e sujeitas à regeneração natural. O tipo de distúrbio, a área atingida, a intensidade, a frequência e a época definem a extensão do dano e a resiliência do ecossistema, que podem variar de acordo com o banco de sementes local, a disponibilidade de propágulos e de dispersores, e as condições edáficas (Godoy, 2001). 
A "capoeirinha" corresponde à segunda fase de sucessão, em que predomina um estrato herbáceo dominado por gramíneas e com poucos arbustos esparsos (Instituto Brasileiro De Geografia E Estatística, 2012). Na Fazenda Remonta, encontram-se nesta fase as áreas ocupadas por pastos abandonados, que perfaz 45\% da área da propriedade (Tabela 1) e trechos colonizados por arbustos de Tithonia diversifolia, espécie exótica invasora denominada popularmente de margaridão ou girassol-mexicano. No caso das pastagens, um dos principais fatores que podem impedir o processo de regeneração natural refere-se à ocupação da área por gramíneas africanas, as quais devem ser alvo de manejo contínuo até a sua erradicação.

É importante destacar que o processo de sucessão dessas áreas pode ser acelerado por meio de técnicas de restauração que aproveitem o potencial de regeneração natural existente. Nessas áreas de pastagem abandonadas, foram identificados muitos indivíduos de espécies pioneiras, tais como Lithrea molleoides (aroeira-brava), Senegalia polyphylla (monjoleiro), Solanum lycocarpum (lobeira), Lonchocarpus campestris (feijão-cru), Gochnatia polymorpha (cambará), entre outras (Tabela 2). Portanto, recomenda-se a condução dessa regeneração natural e, se necessário, o posterior adensamento com espécies pioneiras para as áreas onde essa regeneração mostrar-se insatisfatória para a cobertura do solo.

Como a fonte de propágulos é um dos principais fatores responsáveis pela colonização e pelo enriquecimento de áreas degradadas, a conexão dos fragmentos existentes na paisagem regional certamente irá enriquecer e acelerar o processo de regeneração natural dessas áreas abandonadas. Numa paisagem favorável à regeneração natural, basta remover os agentes degradantes e isolar a área dos fatores de perturbação para estimular a sucessão ecológica, sendo este o meio mais econômico de recuperação florestal, pois estão ausentes os custos com produção e/ou compra de mudas, mão de obra, insumos e manutenção dos plantios (Rodrigues e Gandolfi, 2000; Magnago et al., 2012).

\subsection{4 Áreas antrópicas}

Constituem-se das áreas de solo exposto ou plantio de espécies exóticas, e que ainda estão em uso ou foram abandonadas, mas não estão em processo de regeneração natural. Nesse grupo, foram incluídas as seguintes áreas: pomar, reflorestamento de eucalipto, povoamentos de bambu exótico (Bambusa vulgaris) e bosque de tipuanas (Tipuana tipu) (Figura 3, Tabela 1).

\section{2 Área de Preservação Permanente da Fazenda Remonta}

As margens de rios, cursos d'água, lagos, lagoas e reservatórios são consideradas áreas de preservação permanente (APPs), estando estas cobertas ou não por vegetação nativa. Quando existente, a supressão da vegetação nessas áreas só pode ser autorizada em casos de obras de utilidade pública, de interesse social ou para atividades eventuais de baixo impacto ambiental. Na Fazenda Remonta, as APPs contemplam 59,2 ha, sendo aproximadamente $88 \%$ cobertos por vegetação nativa e o restante ocupado por áreas antrópicas ou degradadas (Figura 4).

Florestas nas margens de cursos d'água são de alto valor ecológico em razão da biodiversidade e de seu alto grau de especialização e endemismo, além dos serviços ecossistêmicos essenciais que desempenham. Existe amplo consenso científico de que são ecossistemas que, para sua estabilidade e funcionalidade, precisam ser conservados ou, se historicamente degradados, restaurados (Silva et al., 2011). Nesse contexto, recomendase a revegetação das áreas degradadas em APP na Fazenda Remonta, as quais deverão ser conduzidas visando à restauração de Floresta Estacional Semidecidual ou Floresta Estacional Aluvial, de acordo com a situação topográfica e as condições edáficas. 


\subsection{Flora da Fazenda Remonta}

Durante o levantamento expedito, foram registradas 50 espécies arbóreas nativas de 46 gêneros e 29 famílias (Tabela 2). Além das espécies nativas, foram observadas 12 espécies exóticas, das quais dez são consideradas invasoras (Tabela 2).

As espécies nativas foram classificadas em grupos sucessionais, classificação esta que se dá por meio das características morfológicas e ecológicas das espécies e é considerada ferramenta eficaz para entender quais grupos de espécies são encontrados em determinada fase sucessional de uma área, quais as características comuns e como ocorre a substituição das espécies ao longo do tempo (Magnago et al., 2012). Uma das classificações em grupos sucessionais mais utilizadas no Brasil é a proposta por Gandolfi et al., (1995). Nesta classificação, a colonização de uma área em processo de sucessão se daria primeiramente pelas espécies pioneiras, que possuem importante papel no sombreamento do solo e na melhoria das condições edáficas, passando, a posteriori, para a predominância, respectivamente, de espécies secundárias iniciais e tardias. Entre as espécies nativas registradas na Fazenda Remonta, 32\% destas foram classificadas como pioneiras, 20\% como secundárias iniciais e 48\% como secundárias tardias (Tabela 2). A presença de espécies nos diferentes grupos sucessionais é um fator positivo para a restauração das áreas da Fazenda, pois evidencia a existência de matrizes e fontes de propágulos para a restauração das áreas degradadas da propriedade.

Entre as espécies observadas na Fazenda (Tabela 2), duas constam na lista oficial de espécies ameaçadas de extinção em escala global: Machaerium villosum (jacarandá-paulista) e Myroxylon peruiferum (cabreúva), ambas na categoria vulnerável à extinção. Não foram registradas espécies ameaçadas em escala nacional ou estadual. Vale lembrar que as espécies citadas foram observadas durante levantamento expedito e, portanto, o esforço amostral foi pequeno. É bastante provável que o número de espécies ameaçadas aumente se forem realizados inventários mais detalhados.

O registro de espécies ameaçadas na Fazenda Remonta revela a importância para a conservação da biodiversidade dos remanescentes de Floresta Estacional Semidecidual presentes no interior paulista. Mesmo fragmentados e sujeitos a diferentes históricos de perturbação, esses habitats ainda abrigam parte importante da flora regional (Franco et al., 2007). No entanto, se medidas visando à conservação e à conexão na paisagem desses remanescentes não forem concretizadas, essas populações de espécies vulneráveis poderão correr um risco ainda maior de extinção local. Por outro lado, a presença de espécies exóticas invasoras na Fazenda Remonta é um indicador de degradação dos remanescentes. Uma "espécie exótica" é aquela que se encontra fora da sua área de distribuição natural. Quando uma espécie exótica é introduzida em um ambiente natural e, a partir do ponto de introdução, se expande via dispersão de propágulos e passa a competir ou deslocar populações de espécies nativas, passa a ser considerada uma "espécie exótica invasora" (Zalba, 2005; Zenni e Ziller, 2011). Dentre as 12 espécies exóticas registradas na Fazenda Remonta, dez são consideradas invasoras e exigem medidas de controle ou erradicação, a fim de diminuir a probabilidade e a magnitude dos impactos que podem causar aos ambientes naturais e à biodiversidade.

\section{REFERÊNCIAS BIBLIOGRÁFICAS}

ACADEMIA DE CIÊNCIAS DO ESTADO DE SÃO PAULO - ACIESP. Glossário de Ecologia. 2. ed. São Paulo: ACIESP; CNPq; FAPESP, 1997. 352 p.

AZEVEDO, C. (Coord.). Estratégia Paulista sobre espécies exóticas invasoras. São Paulo: SMA/SP; CBRN; DPB; CPA, 2009. 58 p. (Relatório do Grupo de Trabalho da Resolução SMA 33/2009, v. 1-2).

BRASIL. Lei $\mathrm{n}^{\circ} 12.651$, de 25 de maio de 2012. Dispõe sobre a proteção da vegetação nativa; altera as Leis $\mathrm{n}^{\text {os }}$ 6.938, de 31 de agosto de 1981, 9.393, de 19 de dezembro de 1996, e 11.428, de 22 de dezembro de 2006; revoga as Leis n ${ }^{\text {os }} 4.771$, de 15 de setembro de 1965, e 7.754, de 14 de abril de 1989, e a Medida Provisória nº 2.166-67, 
de 24 de agosto de 2001; e dá outras providências. Diário Oficial da União, Poder Executivo, Brasília, DF, 28 maio 2012. Disponível em: <http://www.planalto.gov.br/ccivil_03/_Ato2011-2014/2012/Lei/L12651.htm>. Acesso em: 8 ago. 2012.

Ministério do Meio Ambiente. Instrução normativa n ${ }^{\circ}$ 6, de 23 de setembro de 2008. Reconhece as espécies da flora brasileira ameaçadas de extinção. Diário Oficial da União, Poder Executivo, Brasília, DF, 23 set. 2008. Disponível em: <http://www.mma.gov.br/estruturas/179/_arquivos/179_05122008033615.pdf>. Acesso em: 10 ago. 2012.

DURIGAN, G. et al. Fanerógamas. In: RODRIGUES, R. R.; BONONI, V. (Orgs.). Diretrizes para a conservação e restauração da biodiversidade no estado de São Paulo. São Paulo: Instituto de Botânica, 2008. p. 104-109.

. Protocolo de avaliação de áreas prioritárias para a conservação da Mata Atlântica na região da Serra do Mar/Paranapiacaba. Revista do Instituto Florestal, v. 21, n. 1, p. 39-54, 2009.

FRANCO, G. A. D. C. et al. Importância dos remanescentes florestais de Embu - SP para a conservação da flora regional. Biota Neotropica, v. 7, n. 3, p. 145-161, 2007. Disponível em: <http://www.biotaneotropica.org.br/ v7n3/pt/abstract?article+bn02507032007>. Acesso em: 10 out. 2008.

FORZZA, R. C. et al. Lista de Espécies da Flora do Brasil. Rio de Janeiro: Jardim Botânico, 2014. Disponível em: <http://floradobrasil.jbrj.gov.br/>. Acesso em: 3 mar. 2014.

GANDOLFI, S.; JOLY, C. A.; LEITÃO-FILHO, H. F. Gaps of deciduousness: cyclical gaps in Tropical Forests. Scientia Agricola, v. 66, n. 2, p. 280-284, 2009. http://dx.doi.org/10.1590/S0103-90162009000200020.

GANDOLFI, S.; LEITÃO FILHO, H. F.; BEZERRA, C. L. F. Levantamento florístico e caráter sucessional das espécies arbustivo-arbóreas de uma floresta semidecídua no município de Guarulhos, SP. Revista Brasileira de Biologia, v. 55, n. 4, p. 753-767, 1995.

GODOY, J. R. L. Estrutura e composição específica da Mata Atlântica secundária de encosta sobre calcário e filito, no Parque Estadual Turístico do Alto Ribeira, Iporanga, SP. 2001. 57 f. Dissertação (Mestrado em Ecologia)-Universidade de São Paulo, São Paulo, 2001.

INSTITUTO BRASILEIRO DE GEOGRAFIA E ESTATÍSTICA - IBGE. Sistema Fitogeográfico - Classificação da Vegetação Brasileira. In: Manual técnico da vegetação Brasileira. 2. ed. Rio de Janeiro: Instituto Brasileiro de Geografia e Estatística, 2012. 271 p. 62-164

INTERNATIONAL UNION FOR CONSERVATION OF NATURE - IUCN. Lista vermelha de espécies ameaçadas de extinção. 2008. Disponível em: <http://www.iucnredlist.org>. Acesso em: 8 abr. 2014.

INTERNATIONAL UNION FOR CONSERVATION OF NATURE - IUCN. Lista vermelha de espécies ameaçadas de extinção. Cambridge, 2014. Disponível em: <http://www.iucnredlist.org>. Acesso em: 3 mar. 2014.

IVANAUSKAS, N. M.; ASSIS, M. C. Formações florestais brasileiras. In: MARTINS, S. V. (Org.). Ecologia de Florestas Tropicais do Brasil. 2. ed. Viçosa: Editora UFV, 2012. p. 1-371. v. 1.

KÖPPEN, W. Climatologia. México: Fondo Cultura Económica, 1948. 478 p.

KOTCHETKOFF-HENRIQUES, O. Caracterização da vegetação natural em Ribeirão Preto, SP - Bases para conservação. 2003. 221 f. Tese (Doutorado em Biologia Comparada)-Faculdade de Filosofia, Ciências e Letras de Ribeirão Preto, Ribeirão Preto, 2003. 
BERTANI, D.F. et al. Caracterização da vegetação da Fazenda Remonta, Coudelaria de Campinas, São Paulo

KRONKA, F. J. N. et al. Inventário florestal da vegetação natural do Estado de São Paulo. São Paulo: Imprensa Oficial, 2005. 200 p.

LUEDER, D. R. Serial photographic interpretation, principles and applications. New York: MacGraw-Hill, 1959. $462 \mathrm{p}$.

MAGNAGO, L. F. et al. Os processos e estágios sucessionais da Mata Atlântica como referência à restauração florestal. In: MARTINS, S. V. (Org.). Restauração ecológica de ecossistemas degradados. Viçosa: Editora UFV, 2012. p. 69-100. v. 1.

MAMEDE, M. C. H. et al. Livro vermelho das espécies vegetais ameaçadas do Estado de São Paulo. São Paulo: Instituto de Botânica; Imprensa Oficial, 2007. 165 p.

MORELlATO, L. P. C. Características dos padrões fenológicos em florestas estacionais neotropicais. In: CLAUDINO-SALES, V. (Org.). Ecossistemas brasileiros: manejo e conservação. Fortaleza: Expressão Gráfica, 2003. p. 299-304.

RODRIGUES, R. R.; GANDOLFI, S. Conceitos, tendências e ações para a recuperação de florestas ciliares. In: RODRIGUES, R. R.; LEITÃO-FILHO, H. F. (Org.) Matas ciliares: conservação e recuperação. São Paulo: EDUSP; FAPESP, 2000. p. 235-247.

RODRIGUES, R. R.; BONONI, V. Diretrizes para a conservação e restauração da biodiversidade no estado de São Paulo. São Paulo: Instituto de Botânica, 2008. 248 p.

SANTIN, D. A. A vegetação remanescente do município de Campinas (SP): mapeamento, caracterização fisionômica e florística visando à conservação. 1999. 467 f. Tese (Doutorado em Biologia Vegetal)-Universidade Estadual de Campinas, Campinas, 1999.

SILVA, J. A. A. et al. O Código Florestal e a Ciência: contribuições para o diálogo. São Paulo: Sociedade Brasileira para o Progresso da Ciência; Academia Brasileira de Ciências, 2011. 124 p.

SOUZA, V.; LORENZI, H. Botânica Sistemática: guia ilustrado para identificação das famílias de Fanerógamas nativas e exóticas no Brasil, baseado em APGIII. 3. ed. Nova Odessa: Instituto Plantarum, 2012. 768 p.

SPURR, S. H. Photogrammetry and Photointerpratation. 2. ed. New York: Ronald Press Co., 1960. 465 p.

THE ANGIOSPERM PHYLOGENY GROUP III - APGIII. An update of the Angiosperm Phylogeny Group Classification for the orders and families of flowering plants: APG III. Botanical Journal of the Linnean Society, v. 161, n. 2, p. 105-121, 2009. http://dx.doi.org/10.1111/j.1095-8339.2009.00996.x.

WANDERLEY, M. G. L. et al. Checklist das Spermatophyta do Estado de São Paulo, Brasil. Biota Neotropica, v. 11, n. 1a, p. 193-390, 2011. Disponível em: <http://www.biotaneotropica.org.br/v11n1a/pt/abstract?inventory +bn0131101a2011>. Acesso em: 1 ago. 2012.

ZALBA, S. M. Introdução às Invasões Biológicas: conceitos e definições. In: MATTHEWS, S.; BRAND, K. (Eds.). América do Sul invadida: a crescente ameaça das espécies exóticas invasoras. Nairobi: GISP, 2005. p. 4-5.

ZENNI, R. D.; ZILLER, S. R. An overview of invasive plants in BraziI. Revista Brasileira de Botânica, v. 34, n. 3, p. 431-446, 2011. 